\title{
ILC2s Induce Adaptive Th2-Type Immunity in Acute Exacerbation of Chronic Obstructive Pulmonary Disease
}

\author{
Min Jiang, ${ }^{1}$ Huifang Liu, ${ }^{1}$ Zheng Li $\left(\mathbb{D},{ }^{1}\right.$ Jing Wang $\left(\mathbb{D},{ }^{1}\right.$ Fengbo Zhang, ${ }^{2}$ Kaixiu Cao, ${ }^{1}$ \\ Fengsen Li $\left(\mathbb{D},{ }^{1}\right.$ and Jianbing Ding $\mathbb{1}^{3}$ \\ ${ }^{1}$ Xinjiang Laboratory of Respiratory Disease Research, Traditional Chinese Medicine Hospital Affiliated to Xinjiang \\ Medical University, Urumqi 830011, China \\ ${ }^{2}$ Department of Clinical Laboratory, First Affiliated Hospital of Xinjiang Medical University, Urumqi 830054, China \\ ${ }^{3}$ Department of Immunology, College of Basic Medicine, Xinjiang Medical University, Urumqi 830011, China
}

Correspondence should be addressed to Fengsen Li; fengsen602@163.com and Jianbing Ding; 1601379937@qq.com

Received 30 January 2019; Accepted 20 May 2019; Published 20 June 2019

Academic Editor: Eduardo Dalmarco

Copyright (c) 2019 Min Jiang et al. This is an open access article distributed under the Creative Commons Attribution License, which permits unrestricted use, distribution, and reproduction in any medium, provided the original work is properly cited.

To investigate the effect of ILC2s on Th2-type adaptive immunity during the acute exacerbation of chronic obstructive pulmonary disease (AECOPD), the study enrolled healthy people, stable COPD patients, and AECOPD patients. Flow cytometry was used to detect Th1, Th2, and ILC2 in the peripheral blood and CD80 and MHC II levels on ILC2. The mRNA levels of GATA3, ROR $\alpha$, and CRTH2 of ILC2s were detected by RT-PCR. In addition, ILC2s from the peripheral blood of AECOPD patients were cocultured with $\mathrm{CD}^{+} \mathrm{T}$ cells from the peripheral blood of healthy controls. Cytokine levels in serum of the three groups and the in vitro coculture supernatants were measured by ELISA. Compared with the stable COPD group or the healthy control group, Th2 in the peripheral blood of AECOPD group increased dramatically, inducing an increase of Th2/Th1 ratio in AECOPD patients. Meanwhile, the level of IL-4 in the serum of this group was also increased. However, we also detected ILC2s in the peripheral blood of the AECOPD group and found that it was also increased, alone with the increased GATA3, ROR $\alpha$, and CRTH2 mRNA levels. We also found that the CD80 and MHC II on ILC2 were significantly upregulated and the proportion of MHC II ILC2 $^{+}$ cells was significantly positively correlated with the proportion of Th2 cells in AECOPD patients. To further demonstrate the effect of ILC2 on Th2 cells, we cocultured ILC2 with CD4 ${ }^{+}$T cells in vitro, which also showed a significant increase of Th2 ratio as well as Th2-associated cytokines IL-4, IL-5, and IL-13. However, we found that this effect of ILC2s on Th2 cells could be inhibited by the addition of anti-MHC II. The Th2/Th1 balance shifts to Th2 in AECOPD. ILC2s may function as APC by the upregulation of MHC II and regulate adaptive immunity shift to Th2-type response in AECOPD.

\section{Introduction}

Chronic obstructive pulmonary disease (COPD) is a chronic inflammatory disease of the respiratory tract characterized by persistent incomplete reversible airflow limitation $[1,2]$. COPD can develop into acute exacerbation of COPD (AECOPD), featured by symptoms of cough, phlegm, asthma, and dyspnea. In AECOPD, the lung function of patients is rapidly deteriorated, accompanied by inflammation and fever. Recurrent AECOPD is an important factor in promoting the progression of COPD, leading to a decline in the quality of life of patients and an increase in mortality [3-6]. Lower respiratory tract bacterial infection is an impor- tant factor in the occurrence of AECOPD, which can lead to immune dysfunction. Studies also found that the abnormality of $\mathrm{T}$ cell subsets is the main cause of immune dysfunction in COPD [7-9] and Th1/Th2 imbalance may be one of the causes of AECOPD [10]. It is reported that the activation and proliferation of Th2 cells in the peripheral blood of patients with AECOPD were more obvious, resulting in a significant downregulation of Th1/Th2 ratio and a shift to Th2 responses [11]. However, the cause of the shift of the adaptive immunity to the Th2-type immune response in the AECOPD remains unclear.

The type 2 innate lymphoid cells (ILC2s) are the main effecter cells of early Th2-type immune response and play 
an important role in inducing adaptive Th2-type immune response $[12,13]$. ILC2s can rapidly secrete Th2-type cytokines such as IL-5 and IL-13 under the stimulation of intrinsic cytokines such as IL-33 and IL-25, thereby regulating the innate immune system and the adaptive immune system to participate in Th2-type immune responses [14, 15]. Previous study has shown that professional antigen-presenting dendritic cells are essential for inducing Th2-type immune responses by expressing MHC class II molecules [16]. Other cells such as B cells, eosinophils, and ILC2s can also express MHC class II molecules to function as antigen-presenting cells (APC) $[17,18]$. In addition, ILC2s highly express OX40L, ICOS, and ICOSL and costimulatory molecules of CD80 and CD86, which can regulate the differentiation of $\mathrm{CD}^{+} \mathrm{T}$ cells $[19,20]$. Pulmonary inflammation in COPD is characterized by both innate and adaptive immune responses, and ILC2s are involved in the innate immune response [21]. However, the role of ILC2 in regulating Th2-type responses in COPD remains unclear.

In this study, we investigated the effect of ILC2s on Th2type adaptive immunity during AECOPD. We found that ILC2 could play as APC by upregulating CD80 and MHC II molecules, thereby regulating Th2-type immune response in AECOPD.

\section{Materials and Methods}

2.1. Patients. We included outpatients and inpatients from November 2017 to November 2018 in Xinjiang Uygur Autonomous Region Chinese Medicine Hospital, all of whom met the diagnostic criteria for COPD. Among them, 98 patients (59 males and 39 females) were with AECOPD, with an average age of $67 \pm 8.5$ years. There were 112 patients (68 males and 44 females) with stable COPD, with an average age of $67 \pm 8.2$ years. We also enrolled 110 healthy controls (69 males and 41 females) with an average age of $66 \pm$ 6.9 years. The demographic information and medical history of patients were recorded (Table 1), and all the patients were scored using the COPD Assessment Test (CAT) Scale and the Modified Medical Research Council (mMRC) Dyspnea Scale. The six-minute walk distance (6MWD) was also measured. Informed consent was obtained from each patient. The project was approved by the Ethics Committee of Xinjiang Uygur Autonomous Region Chinese Medicine Hospital.

2.2. Diagnosis Inclusion and Exclusion Criteria. COPD and AECOPD diagnostic criteria were in line with the Global Strategy for the Diagnosis, Management, and Prevention of Chronic Obstructive Pulmonary Disease (2011 Revision), published jointly by the American Thoracic Society and the European Respiratory Society [22]. Inclusion criteria for COPD were as follows: (1) patients with COPD diagnosed based on clinical manifestations (such as chronic cough, cough, and/or dyspnea), exposure history of risk factors, physical signs, and pulmonary function tests; (2) patients with incomplete reversible airflow limitation (FEV1/FVC < $70 \%$ after bronchodilator). At the same time, the AECOPD group also met the following criteria: COPD patients had cough in a short term and the cough was aggravated accom- panied by purulent sputum, asthma, dyspnea, and fever. Exclusion criteria were as follows: (1) patients with other respiratory diseases or other systemic infections; (2) patients with serious primary diseases such as severe cardiovascular diseases, hepatorenal diseases, and hematopoietic system diseases; and (3) patients who used antibiotics, systemic glucocorticoids, or immunosuppressants within 30 days before enrolment. All the healthy controls were of neither symptom of infection nor abnormal lung function.

2.3. Sampling. The peripheral blood was collected before antibiotic or hormone therapy. PBMCs were isolated from the whole blood by Ficoll density gradient method. The whole blood was collected from all subjects and then placed at room temperature for $30 \mathrm{~min}$. Then, the serum was separated by centrifugation at $3000 \mathrm{rpm}$ for $10 \mathrm{~min}$, and the serum was stored at $-80^{\circ} \mathrm{C}$ until use.

2.4. Flow Cytometry. For detection of Th1 and Th2, $200 \mu \mathrm{L}$ of peripheral blood was incubated with an equal volume of RPMI-1640 medium along with $2 \mu \mathrm{L}$ Leukocyte Activation Cocktail, with BD GolgiPlug (550583, BD, San Jose, CA, USA) at $37^{\circ} \mathrm{C}, 5 \% \mathrm{CO}_{2}$ for $6 \mathrm{~h}$. Then, the cells were stained with APC-Cy7-CD3 (SK7, BD, San Jose, CA, USA) and FITC-CD4 (RPA-T4, BD, San Jose, CA, USA) for $30 \mathrm{~min}$ at room temperature. After that, cells were fixed and permeabilized at $4^{\circ} \mathrm{C}$ for $40-50$ minutes in the dark. After washing, the cells were stained with APC-IFN- $\gamma$ (B27, BD, San Jose, CA, USA), PE-IL-4 (8D4-8, BD, San Jose, CA, USA) at $4^{\circ} \mathrm{C}$ for 40-50 min in the dark. Then, the percentage of $\mathrm{CD}^{+-}$ $\mathrm{CD} 4^{+} \mathrm{IFN}-\gamma^{+} \mathrm{T}$ cells and $\mathrm{CD} 3^{+} \mathrm{CD} 4^{+} \mathrm{IL}-4^{+} \mathrm{T}$ cells was measured by flow cytometry.

For detection of CD80/MHC II of ILC2, $200 \mu \mathrm{L}$ of peripheral blood was incubated with the following antibodies (all from BD unless mentioned), including Lineage-FITC, CD3 (UCHT1), CD19 (HIB19), CD123 (7G3), CD11b (M1/70), CD11c (B-ly6), CD8 (RPA-T8), FceRI (AER-37 (CRA-1)), CD14 (M5E2), CD4 (RPA-T4), CD56 (B159), CD45-APC-Cy7 (2D1), CRTH2-PerCP-Cy5.5 (BM16), CD127-PE-Cy7 (HIL-7R-M21), HLA-DR-APC (G46-6), and PE-CD80 (L307.4) at room temperature for $30 \mathrm{~min}$ in the dark. The cells were lysed using red blood cell lysate for 10-15 min. After washing, the cells were resuspended, and the percentage of $\mathrm{Lin}^{-} \mathrm{CD} 45^{+} \mathrm{CD} 127^{+} \mathrm{CRTH} 2^{+}$cells and $\mathrm{Lin}^{-}$ $\mathrm{CD} 45^{+} \mathrm{CD} 127^{+} \mathrm{CRTH} 2^{+} \mathrm{HLA}-\mathrm{DR}^{+}$and $\mathrm{Lin}^{-} \mathrm{CD} 45^{+} \mathrm{CD} 127^{+}$ $\mathrm{CRTH} 2^{+} \mathrm{CD} 80^{+}$cells was detected by flow cytometry.

All flow analyses were performed using the LSR II flow cytometer (BD, USA) and analyzed using the Kaluza software (Beckman Coulter Inc.).

2.5. Cell Sorting. Peripheral blood of the healthy control group, the stable COPD group, and the AECOPD group was collected, and ILC2s from each group were then sorted by magnetic beads (STEMCELL, Vancouver, BC, Canada). The CD $4^{+} \mathrm{T}$ cells were sorted from the peripheral blood of healthy controls with magnetic beads (Miltenyi Biotec, Bergisch Gladbach, Germany).

2.6. Real-Time PCR. Total RNA was extracted from ILC2s using TRIzol LS (Takara, Tokyo, Japan). Then, the cDNA 
TABLE 1: The clinical data of the study cohort.

\begin{tabular}{|c|c|c|c|c|c|c|}
\hline Factors & Healthy control $(n=110)$ & Stable COPD $(n=112)$ & $\operatorname{AECOPD}(n=98)$ & $P$ value* & $P$ value** & $P$ value*** \\
\hline Age & $66 \pm 6.9$ & $67 \pm 8.2$ & $67 \pm 8.5$ & 0.45 & 0.18 & 0.64 \\
\hline \multicolumn{7}{|l|}{ Gender $n(\%)$} \\
\hline Male & $69(62.7)$ & $68(60.7)$ & $59(60.2)$ & $>0.05$ & $>0.05$ & $>0.05$ \\
\hline Female & $41(37.3)$ & $44(39.3)$ & $39(39.8)$ & $>0.05$ & $>0.05$ & $>0.05$ \\
\hline Stages & - & $16.4 \pm 15.04$ & $17.3 \pm 12.3$ & & $>0.05$ & $>0.05$ \\
\hline \multicolumn{7}{|c|}{ History of smoking $n(\%)$} \\
\hline Yes & $78(69.6)$ & $76(67.9)$ & $66(67.3)$ & $>0.05$ & $>0.05$ & $>0.05$ \\
\hline No & $32(31.4)$ & $36(32.1)$ & $31(32.7)$ & $>0.05$ & $>0.05$ & $>0.05$ \\
\hline \multicolumn{7}{|c|}{ Pulmonary function } \\
\hline FEV1/FVC & $79 \pm 5.18$ & $61.5 \pm 5.79$ & $52.6 \pm 7.5$ & $<0.01$ & $<0.01$ & $<0.01$ \\
\hline FEV1\% & $90.6 \pm 12.9$ & $65.38 \pm 10.67$ & $39.23 \pm 7.8$ & $<0.01$ & $<0.01$ & $<0.01$ \\
\hline $\mathrm{FVC} \%$ & $96.07 \pm 13.7$ & $86.91 \pm 15.09$ & $60.5 \pm 12.9$ & $<0.01$ & $<0.01$ & $<0.01$ \\
\hline \multicolumn{7}{|c|}{ Patient physical index } \\
\hline BMI & $24.75 \pm 2.76$ & $25.1 \pm 3.4$ & $24.5 \pm 3.9$ & $>0.05$ & $>0.05$ & $>0.05$ \\
\hline 6MWD (m) & $416 \pm 79$ & $411 \pm 71$ & $392 \pm 70$ & $>0.05$ & $>0.05$ & $>0.05$ \\
\hline mMRC & $2(1,2)$ & $2(1,2)$ & $2(2,2)$ & $>0.05$ & $<0.05$ & $>0.05$ \\
\hline CAT & $7(4,10)$ & $9(7,14)$ & $10(6,15)$ & $>0.05$ & $<0.05$ & $<0.05$ \\
\hline \multicolumn{7}{|c|}{ Inflammatory cytokines } \\
\hline IL-4 (pg/mL) & $29.71 \pm 5.96$ & $36.88 \pm 3.05$ & $55.16 \pm 7.37$ & $<0.5$ & $<0.01$ & - \\
\hline IFN- $\gamma(\mathrm{pg} / \mathrm{mL})$ & $26.35 \pm 4.67$ & $27.97 \pm 10.52$ & $36.13 \pm 11.80$ & $<0.5$ & $<0.01$ & - \\
\hline
\end{tabular}

AECOPD: acute exacerbations of chronic obstructive pulmonary disease; BMI: body mass index; COPD: chronic obstructive pulmonary disease; FEV1: forced expiratory volume in one second; FVC: forced vital capacity. FEV1/FVC was determined post bronchodilator. IL-4: interleukin-4; IFN- $\gamma$ : interferon- $\gamma$; $6 \mathrm{MWD}$ : 6-minute walk distance; mMRC: Modified Medical Research Council Dyspnea Scale; CAT: Assessment Test Scale. Data were presented by mean \pm SD, median (P25, P75), or percentage. The comparison between two groups was determined by $t$-test, Mann-Whitney $U$ test, or chi-square test. A $P<0.05$ was considered statically significant. ${ }^{*}$ Comparison between AECOPD patients and stable COPD patients. ${ }^{* *}$ Comparison between AECOPD patients and HCs. ${ }^{* * *}$ Comparison between stable COPD patients and HCs.

TABle 2: Primers for RT-PCR.

\begin{tabular}{|c|c|c|c|c|c|}
\hline Gene & Genbank accession & $\begin{array}{l}\text { Forward primer } \\
\qquad\left(5^{\prime} \rightarrow 3^{\prime}\right)\end{array}$ & $\begin{array}{l}\text { Reverse primer } \\
\quad\left(5^{\prime} \rightarrow 3^{\prime}\right)\end{array}$ & $\begin{array}{c}\text { Product size } \\
\text { (bp) }\end{array}$ & $\begin{array}{l}\mathrm{Tm} \\
\left({ }^{\circ} \mathrm{C}\right)\end{array}$ \\
\hline CRTH2 & NM_004778.2 & CGCCACACTGAAGCCACTCTG & 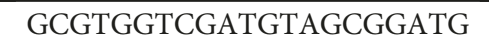 & 90 & 60 \\
\hline RORA & NM_002943.3 & CTGGTGTGCATAGCGGAGGTTG & CCTGCGGACTGGCAATAATCGG & 101 & 60 \\
\hline GATA3 & NM_001002295.1 & GTGCATGACTCACTGGAGGACTTC & CATGTGGCTGGAGTGGCTGAAG & 114 & 60 \\
\hline GAPDH & NM_002046 & CAGGAGGCATTGCTGATGAT & GAAGGCTGGGGCTCATTT & 138 & 60 \\
\hline
\end{tabular}

was synthesized from the isolated total RNA using Transcriptor first strand cDNA synthesis kit (Takara, Tokyo, Japan). The mRNA levels of CRTH2, GATA3, and ROR $\alpha$ were detected with real-time PCR by using BIO-RAD CFX96 detection system. Primers for these genes are listed in Table 2. The PCR procedure was as follows: $95^{\circ} \mathrm{C}$ for 5 min, followed by 40 cycles of $95^{\circ} \mathrm{C}$ for $30 \mathrm{~s}$ and $60^{\circ} \mathrm{C}$ for 30 s. The expression levels were calculated with $2^{-\triangle \triangle \mathrm{CT}}$ method and normalized to GAPDH.

2.7. Coculture. The sorted ILC2s from AECOPD patients were seeded at 500 cells/well in 96-well plates and cultured with incomplete IMDM medium supplemented with 500 ng/mL IL-2 (200-02-10, PeproTech, Rocky Hill, NJ, USA), 500 ng/mL IL-25 (8134-IL-025, R\&D, Minneapolis, MN, USA), $500 \mathrm{ng} / \mathrm{mL}$ IL-33 (R\&D, Minneapolis, MN, USA), and 500 ng/mL TSLP (300-62-10, PeproTech, Rocky Hill, NJ, USA) for 5 days. The $\mathrm{CD}^{+}{ }^{+} \mathrm{T}$ cells sorted from healthy controls were then seeded at $1 \times 10^{5} /$ well in 96-well plates.

ILC2 and $\mathrm{CD}^{+} \mathrm{T}$ cells were then cocultured at $1: 1$ ratio and were divided into coculture group, anti-MHC class II $\mathrm{mAb}(20 \mathrm{mg} / \mathrm{mL}$, eBioscience) blocking group, and antiMHC isotype (eBioscience) control group. The cells were incubated at $37^{\circ} \mathrm{C}, 5 \% \mathrm{CO}_{2}$ for 4 days. After that, the culture supernatant was collected. Then, the $\mathrm{CD} 3^{+} \mathrm{CD} 4^{+} \mathrm{IL}-4^{+}$cells were analyzed by flow cytometry.

2.8. ELISA. Levels of IL-5, IL-13, IL-4, and IFN- $\gamma$ in serum and the coculture supernatant were measured by double antibody sandwich enzyme-linked immunosorbent assay (ELISA) kits. All ELISA kits were purchased from Hangzhou Lianke Biotechnology Co. Ltd. (Hangzhou, China). Briefly, 


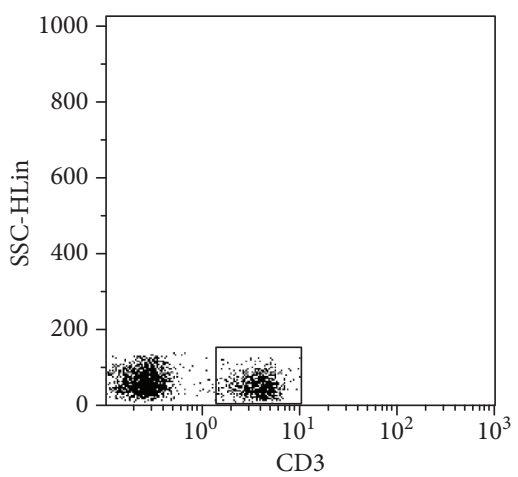

(a)
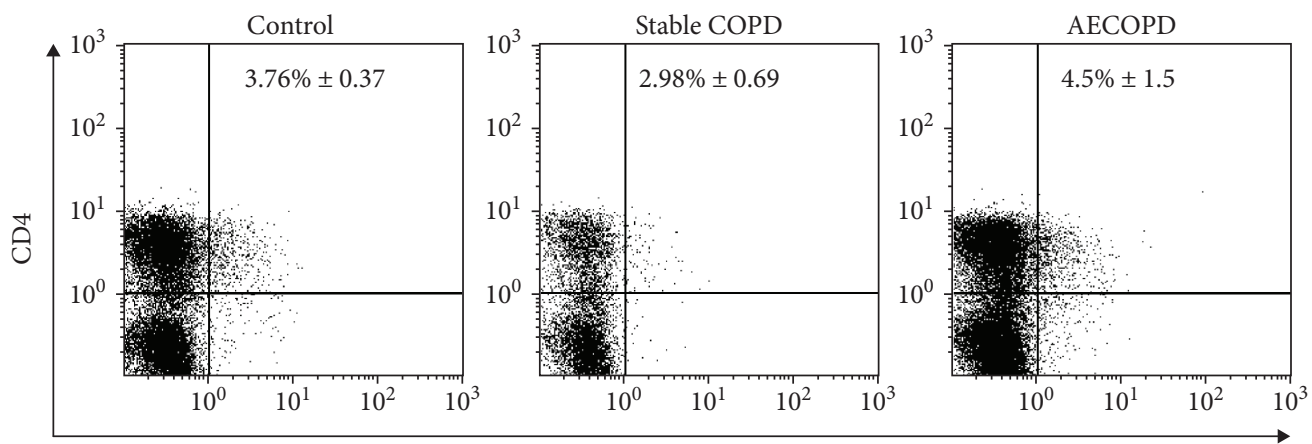

IL-4

(b)
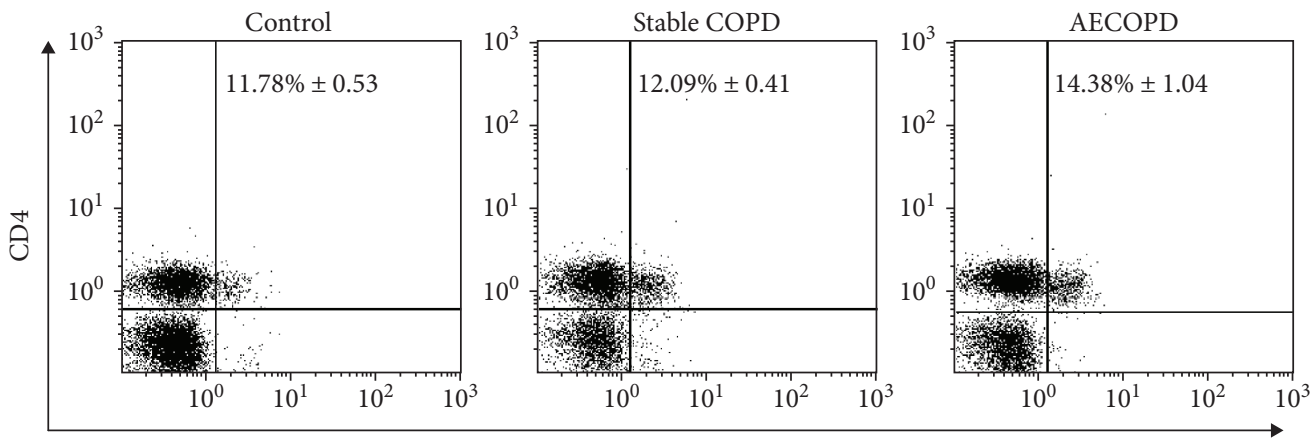

IFN- $\gamma$

(c)

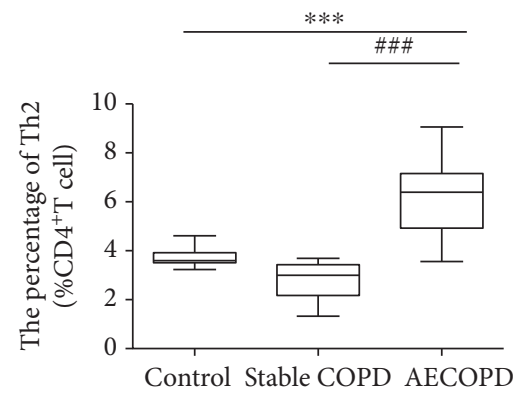

(d)

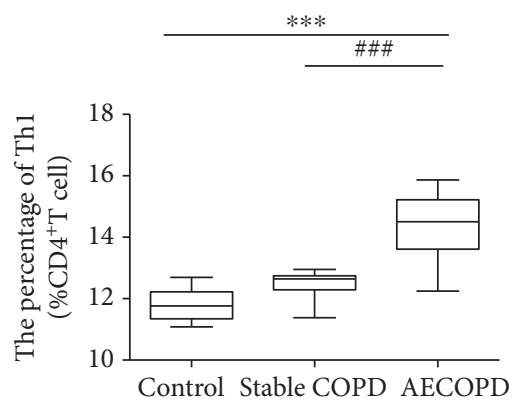

(e)

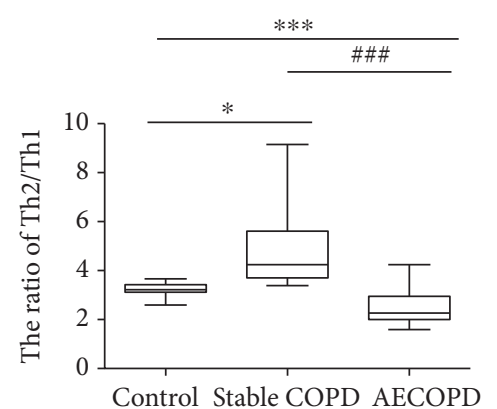

(f)

Figure 1: Percentage of Th2 cells and Th1 cells in the peripheral blood of three groups. Th2 cells and Th1 cells from healthy control, stable COPD, and AECOPD groups were analyzed by flow cytometry. (a) $\mathrm{CD}^{+} \mathrm{T}$ lymphocytes. SSC/CD3 was gated. (b) Intracellular expression of IL- 4 on $\mathrm{CD}^{+} \mathrm{CD}^{+} \mathrm{T}$ cells. (c) Intracellular expression of IFN- $\gamma$ on $\mathrm{CD} 3^{+} \mathrm{CD} 4^{+} \mathrm{T}$ cells. (d) Percentage of Th 2 cells. (e) Percentage of Th1 cells. (f) Th2/Th1 ratio among healthy control, stable COPD, and AECOPD groups. Data are shown as mean $\pm \mathrm{SD}$; ${ }^{*} P<0.05,{ }^{* * *} P<0.001$, indicating comparison with the control group. ${ }^{\# \# \#} P<0.001$ indicating comparison with the stable COPD group. 


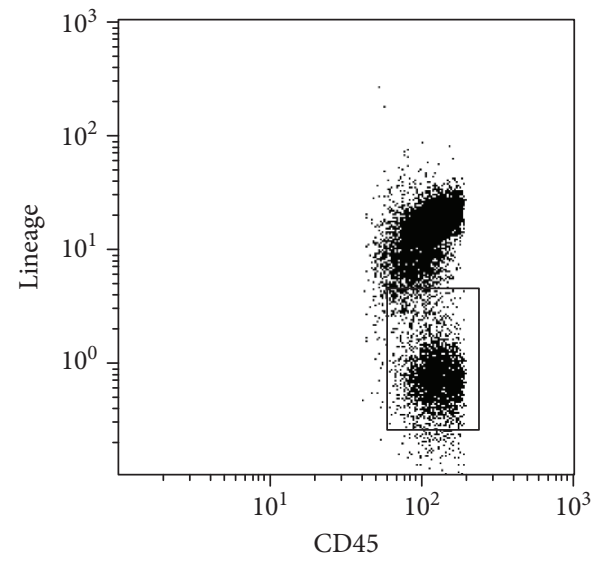

(a)
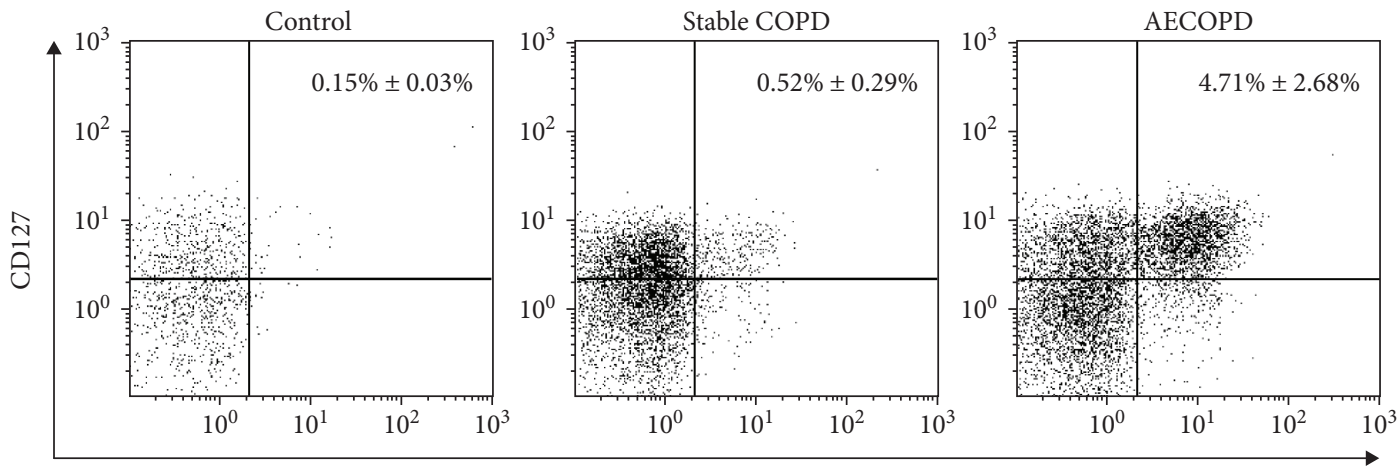

CRTH2

(b)

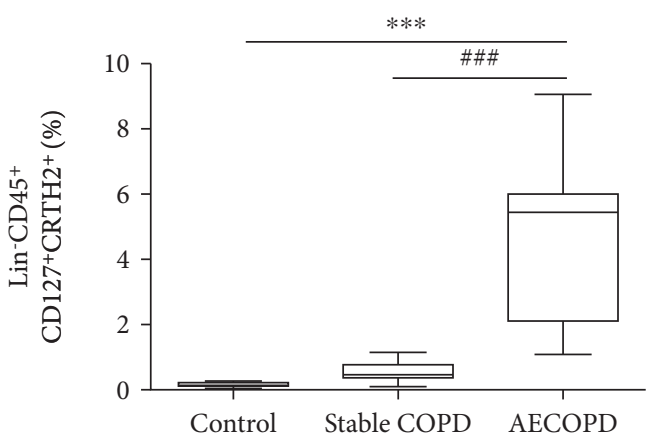

(c)

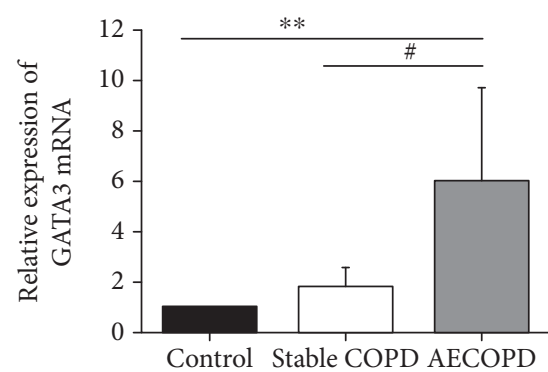

(e)

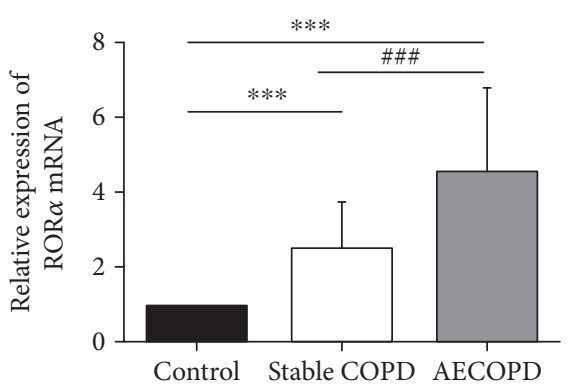

(d)

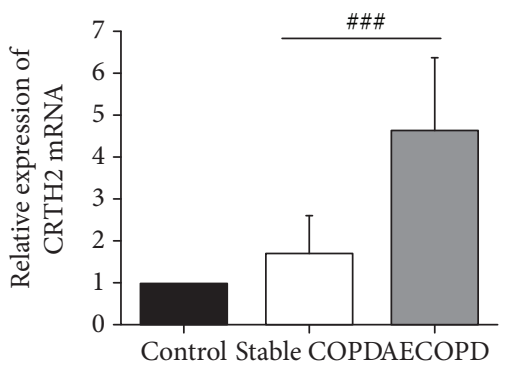

(f)

FIGURE 2: Levels of ILC2 and the related transcription factors of the three groups. Flow cytometry was performed. (a-c) Percentage of ILC2s in the peripheral blood of control, stable COPD group, and AECOPD group. The mRNA levels of (d) ROR $\alpha$, (e) GATA3, and (f) CRTH2 were tested by RT-PCR. Data were normalized to control group and represented as mean \pm SD. Compared with the control group, ${ }^{* *} P<0.01$, ${ }^{* * *} P<0.001$. Compared with the stable COPD group, ${ }^{\#} P<0.05$, \#\#\# $P<0.001$. 


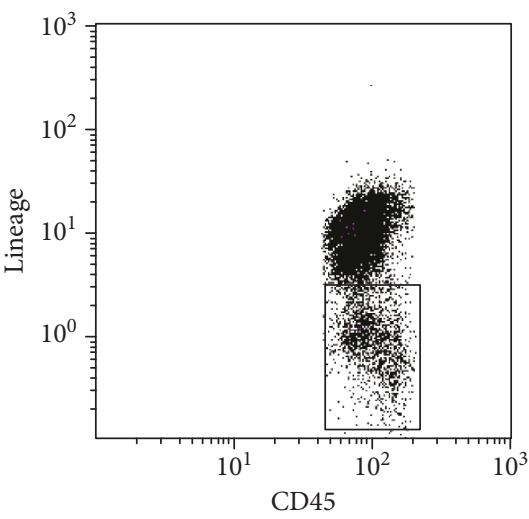

(a)
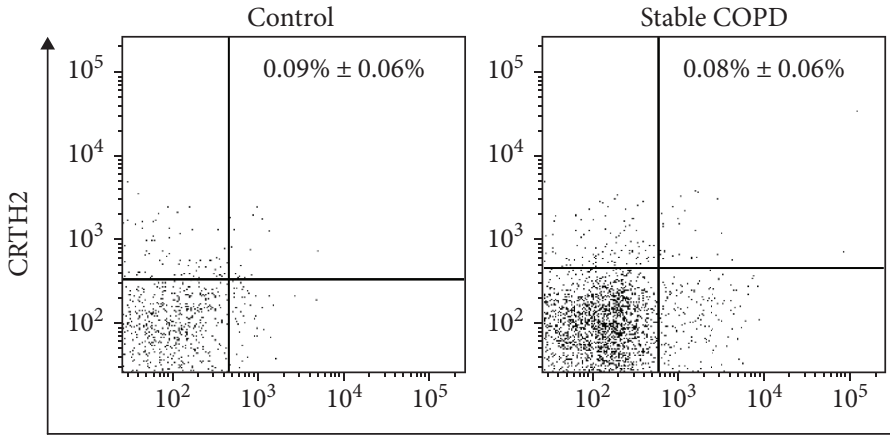

(b)

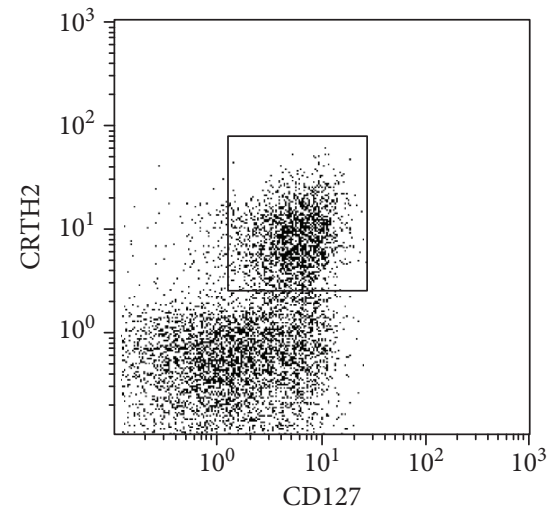

CD80

(c)

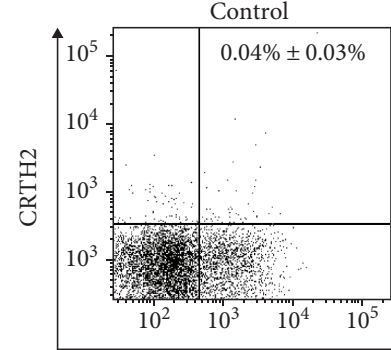

Stable COPD

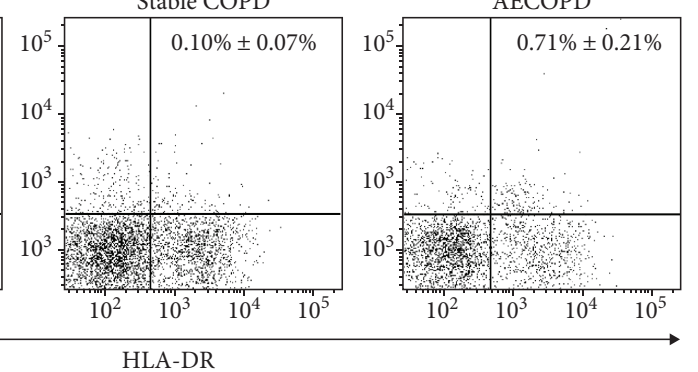

(d)

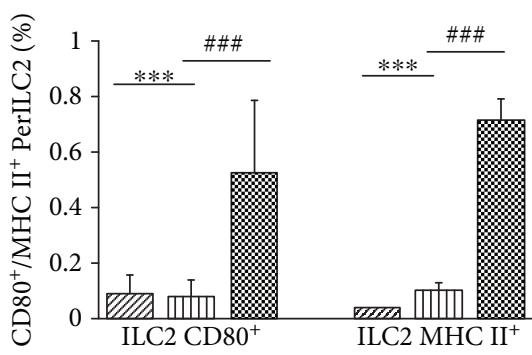

ए7 $\mathrm{HC}$

血 Stable COPD

AECOPD

(e)

FIgURE 3: The level of MHC II and CD80 on ILC2s. Flow cytometry was performed. (a) Flow cytometric analysis of lineage-negative CD45 cells is shown. (b) ILC2s are identified as Lin ${ }^{-} \mathrm{CD} 45^{+} \mathrm{CD} 127^{+} \mathrm{CRTH} 2^{+}$. (c) CD80 and (d) MHC II on the surface of ILC2 in healthy control, stable COPD, and AECOPD groups. (e) The statistical results of percentage of CD $80^{+}$and $\mathrm{MHC} \mathrm{II}^{+}$within $\mathrm{Lin}^{-} \mathrm{CD} 45^{+} \mathrm{CD} 127^{+} \mathrm{CRTH} 2^{+}$cells in each group. Compared with the control group, ${ }^{* * *} P<0.001$. Compared with the stable COPD group, $\# \# \#<0.001$. 
TABLE 3: The correlations between Th2, ILC2 CD80 ${ }^{+}$cells, and ILC2 MHC II ${ }^{+}$cells.

\begin{tabular}{lccc}
\hline Th2 cell & & ILC2 $\mathrm{CD}^{+}$cell & ILC2 $\mathrm{MHC} \mathrm{II}^{+}$cell \\
\hline \multirow{2}{*}{ Stable COPD } & $r$ & 0.126 & 0.439 \\
& $P$ & 0.694 & 0.133 \\
\multirow{2}{*}{ AECOPD } & $r$ & 0.482 & 0.641 \\
& $P$ & 0.095 & 0.018 \\
\hline
\end{tabular}

an ELISA plate was coated with capture antibody. The serum or sample supernatant was then added, and horseradish peroxidase-conjugated secondary monoclonal antibody was added. After washing with PBST three times, tetramethylbenzidine was added in the dark for colour development. Absorbance was determined at $450 \mathrm{~nm}$ and a reference wavelength of $570 \mathrm{~nm}$ using a spectrophotometer. Concentrations were calculated based on a standard curve.

2.9. Statistical Analysis. Statistical analysis was performed using GraphPad Prism 5 (GraphPad Software Inc., San Diego, CA, USA). Measurement data are expressed as mean \pm standard deviation (SD). One-way ANOVA and MannWhitney $U$ test were used to compare the data among multiple groups. The $t$-test was used for the comparison between two groups. Count data were expressed as percentages and analyzed by $\chi^{2}$ test. Pearson correlation analysis was used for correlation analysis. $P<0.05$ means statistical difference and $P<0.01$ means that the difference is extremely significant.

\section{Results}

3.1. Clinical Data of Patients. A summary of patient demographics is shown in Table 1 . The body mass index (BMI) was $24.5 \pm 3.9 \mathrm{~kg} / \mathrm{m}^{2}$ in the AECOPD group, $25.1 \pm 3.4 \mathrm{~kg} /$ $\mathrm{m}^{2}$ in the stable COPD group, and $24.75 \pm 2.76 \mathrm{~kg} / \mathrm{m}^{2}$ in HCs. No difference of demographic characteristics was found among groups. Forced expiratory volume in one second FEV1/forced vital capacity (FVC) of AECOPD patients was obviously lower than that in stable COPD patients and HCs (all $P<0.001$ ). In addition, $\mathrm{FEV} 1 \%$ and $\mathrm{FVC} \%$ of AECOPD patients were also obviously lower than those in the other two groups. Compared with healthy controls, the mMRC score and CAT results of AECOPD patients were significantly increased $(P<0.05)$. Besides, IL- 4 and IFN- $\gamma$ expression in AECOPD patients was markedly higher than that in stable COPD patients $(P<0.05)$.

3.2. Th2/Th1 Balance Shifts to Th2 in AECOPD. We used flow cytometry to detect the changes of Th1 and Th2 cells in peripheral blood of the AECOPD group, the stable COPD group, and the healthy group, respectively. $\mathrm{CD}^{+} \mathrm{T}$ lymphocytes were gated (Figure 1(a)). Compared with the control group and the stable COPD group, the proportion of peripheral blood Th2 (Figures 1(b) and 1(d)) and Th1 cells (Figures 1(c) and $1(\mathrm{e})$ ) in $\mathrm{CD}^{+} \mathrm{T}$ cells was significantly increased in the AECOPD group $(P<0.001)$. At the same time, the AECOPD group had significantly higher proportion of peripheral blood Th2 and Th1 cells in CD $4^{+} \mathrm{T}$ cells than the stable COPD group $(P<0.001)$. However, the ratio of $\mathrm{Th} 2 / \mathrm{Th} 1$ in the peripheral blood of the stable COPD group decreased, while that of the AECOPD group increased significantly than the control group (Figure 1(f)) $(P<0.001)$. The AECOPD group had significantly higher Th2/Th1 ratio than the stable COPD group $(P<0.001)$. These results suggest that there are different Th2/Th1 shifts in different courses of COPD, and in AECOPD, Th2/Th1 balance shifts to the Th2.

3.3. ILC2s in the Peripheral Blood of AECOPD Are Significantly Increased. In this study, we followed the strategy used by Mjosberg et al. [23] to identify ILC2s. We used lineage antibodies, including anti-CD3, CD19, CD123, CD11b, CD11c, CD8, CD14, CD4, CD56, and FceRI $\alpha$ to identify T cells, monocytes, neutrophils, B cells, NK cells, mast cells, and basophils. Lin $^{-}$cells, which are negative for these lineage markers, were gated. ILC2s were expressed as Lineage $\mathrm{CD}^{-} 5^{+} \mathrm{CD} 127^{+} \mathrm{CRTH} 2^{+}$cells. The proportion of ILC2s in the peripheral blood of the AECOPD group, the stable COPD group, and the healthy group was detected by flow cytometry. Lineage $\mathrm{CD}^{-} 5^{+}$cells are shown in Figure 2(a), and the Lineage $\mathrm{CD}^{-} 5^{+} \mathrm{CD} 127^{+} \mathrm{CRTH} 2^{+}$cells are shown in Figure 2(b). The percentage of ILC2s in the peripheral blood of the AECOPD group $(4.71 \% \pm 2.68 \%)$ was significantly higher than that in the stable COPD group $(0.52 \% \pm 0.29 \%)$ and in the healthy group $(0.15 \% \pm 0.03 \%)$ $(P<0.001)$ (Figures 2(b) and 2(c)). Additionally, the AECOPD group had higher percentage of ILC2s than the stable COPD group $(P<0.001)$.

Studies [23-25] have shown that the transcription factors $\operatorname{ROR} \alpha$ and GATA3 are important in the differentiation of ILC progenitor cells into ILC2s. By using real-time PCR, we measured the mRNA levels of these transcription factors in each group of ILC2s. The results showed that the levels of transcription factors $\operatorname{ROR} \alpha$ and GATA3 mRNA in the AECOPD group were significantly higher than those in the healthy control group and the stable COPD group $(P<0.001$, Figures $2(\mathrm{~d})$ and $2(\mathrm{e})) . \mathrm{ROR} \alpha$ and GATA3 mRNA levels in the COPD group were also significantly higher than those in the healthy control group $(P<0.001)$. Moreover, it is reported that after stimulation, ILC2s express high levels of CRTH2 to promote production of Th2-type cytokines [26]. Similarly, our results also showed that CRTH2 mRNA levels were significantly higher in the AECOPD group than in the stable COPD group and the healthy control group $(P<0.001$, Figure $2(f))$. The results indicated that ILC2s might be involved in the pathogenesis of COPD.

3.4. ILC2s in Patients with AECOPD Have High Expression of MHC II and CD80. By using flow cytometry, we further examined the expression of MHC II and CD80 on the surface of ILC2s in the AECOPD group, the stable COPD group, and the healthy control group, respectively (Figure 3). Lineage $\mathrm{CD}^{-} 5^{+}$cells are shown in Figure 3(a), and the Lineage $\mathrm{CD}^{-} 5^{+} \mathrm{CD} 127^{+} \mathrm{CRTH} 2^{+}$cells are shown in Figure $3(\mathrm{~b})$. Compared with the healthy control group, the ILC2 $\mathrm{CD}^{+} 0^{+}$cells in the stable COPD group were 


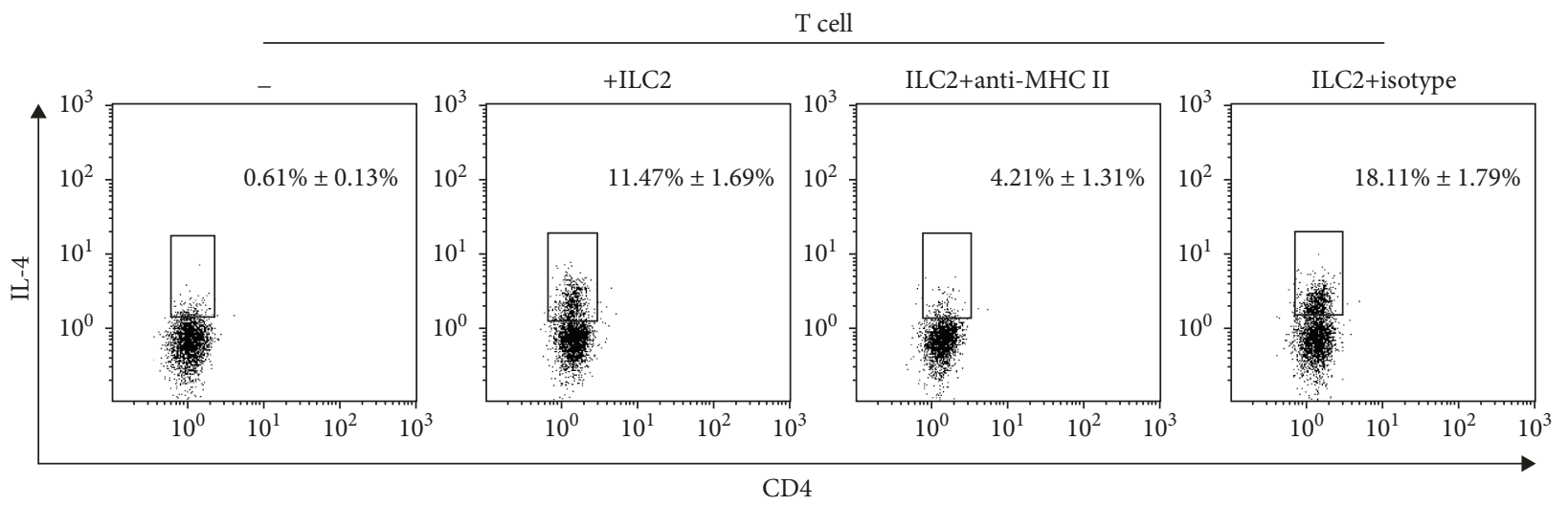

(a)

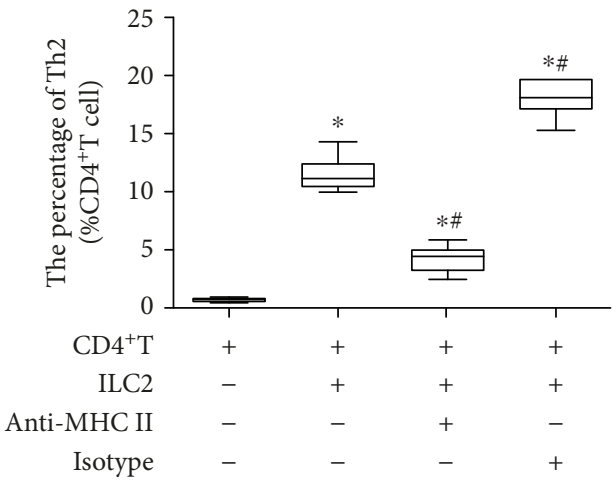

(b)

FIGURE 4: Level of Th2 cells after coculture with ILC2. Flow cytometry was performed. (a) Intracellular IL-4 staining following coculture of ILC2 and CD $4{ }^{+} \mathrm{T}$ cell. (b) Percentage of Th2 cells. Data are shown as mean $\pm \mathrm{SD}$. Compared with the CD $4^{+} \mathrm{T}$ cell group, ${ }^{*} P<0.0$. Compared with the ILC2 group, ${ }^{\#} P<0.01$. Compared with the ILC2+anti-MHC II cell group, ${ }^{\triangle} P<0.01$.

slightly less but significantly increased in the AECOPD group $(P<0.001$, Figures $3(\mathrm{c})$ and $3(\mathrm{e}))$. There was also a slight increase of $\mathrm{MHC} \mathrm{II}^{+}$ILC2 cells in the stable COPD group compared with the healthy control group, but there was no statistical significance. In contrast, the number of $\mathrm{MHC} \mathrm{II}^{+} \mathrm{ILC} 2$ cells in the AECOPD group increased significantly compared to the healthy control and stable COPD groups $(P<0.001$, Figures $3(\mathrm{~d})$ and 3(e)). The high expression of MHC class II molecules and costimulatory molecule CD80 on the surface of ILC2s in the AECOPD group suggests that ILC2s may participate in the immune modulatory process of AECOPD by affecting the function of $\mathrm{CD}^{+} \mathrm{T}$ cells.

3.5. Th2 Cells in the AECOPD Group Were Positively Correlated with MHC II ILC2 Cells. Subsequently, we analyzed the correlation between Th2 cells and ILC2s expressing CD80 and MHC II in the stable COPD group and the AECOPD group. Pearson correlation analysis showed that there was no significant correlation between Th2 cells and $\mathrm{CD}^{+} 0^{+}$ILC2 cells and $\mathrm{MHC} \mathrm{II}^{+}$ILC2 cells in the stable COPD group (Table 3 ). Similarly, Th2 cells in the AECOPD group were not significantly correlated with $\mathrm{CD} 80^{+}$ILC2 cells. However, there was a significant positive correlation between the ratio of Th2 cells and the ratio of $\mathrm{MHC} \mathrm{II}^{+}$ ILC2 cells in the AECOPD group $(r=0.641, P=0.018)$. The results indicated that $\mathrm{MHC} \mathrm{II}^{+}$ILC2 might promote Th2 immunity in AECOPD.

3.6. MHC II ILC2 Promotes Differentiation of Th2 Cells in $A E C O P D$. To determine the function of ILC2 on the differentiation of Th2 cells, we sorted out ILC2s from the peripheral blood of the AECOPD group patients and $\mathrm{CD} 4^{+} \mathrm{T}$ cells from the peripheral blood of healthy donors using magnetic bead sorting. Then, we cocultured ILC2s with CD4 T cells at a $1: 1$ ratio. Flow cytometry result found that ILC2s derived from the AECOPD group promoted the differentiation of $\mathrm{CD}^{+}{ }^{+} \mathrm{T}$ cells into Th2 cells (Figure 4). However, when we used the anti-MHC II neutralizing antibody to interfere with the interaction of MHC II with T cells, the number of Th2 cells decreased. At the same time, the ELISA results showed that IL-4, IL-13, and IL-5 were highly expressed in the culture supernatant after coculture of ILC2 with CD4 T cells (Figures 5(a)-5(c)). However, when anti-MHC II antibody was added, the levels of IL-4, IL-13, and IL-5 were significantly reduced. However, no significant difference in IFN- $\gamma$ was observed in each group (Figure 5(d)). Through in vitro experiments, we confirmed that ILC2 of AECOPD could 


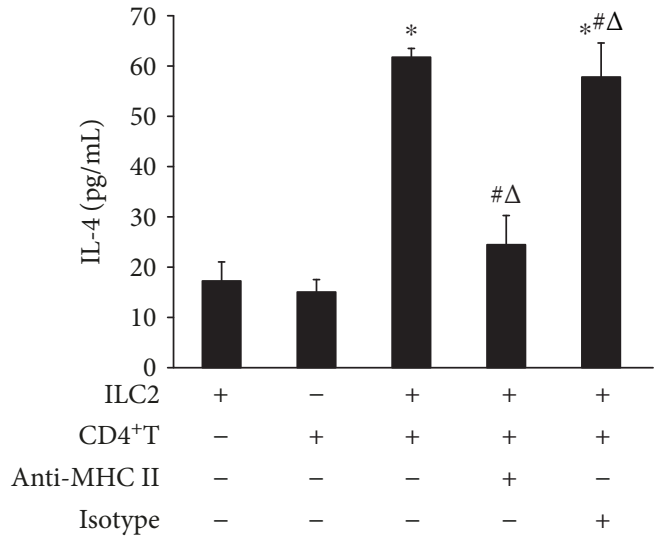

(a)

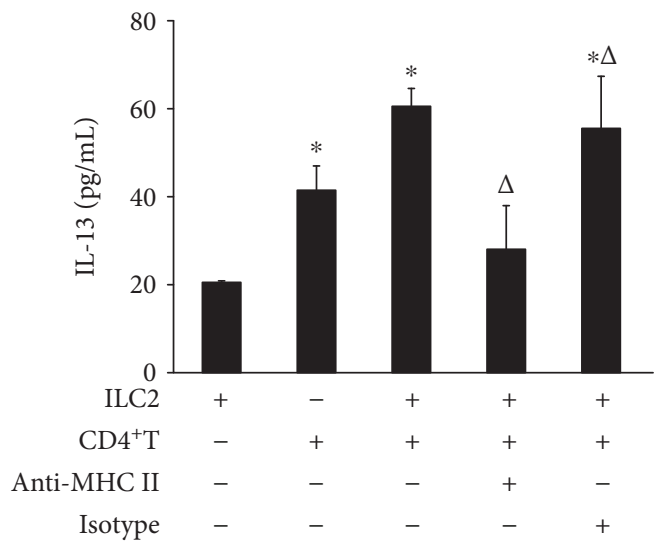

(c)

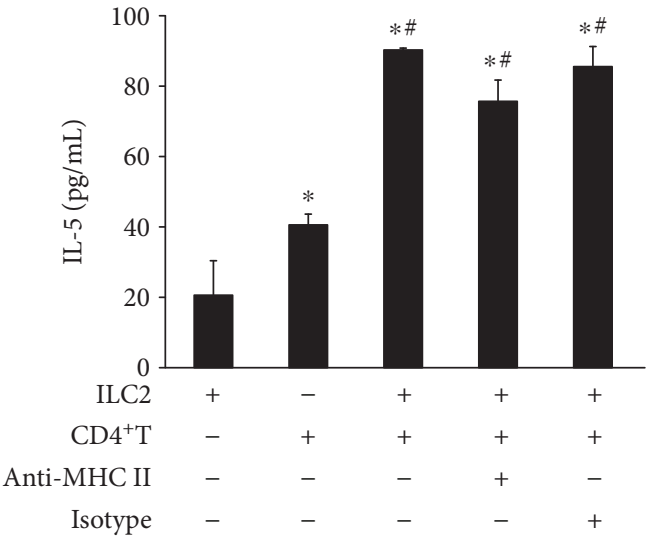

(b)

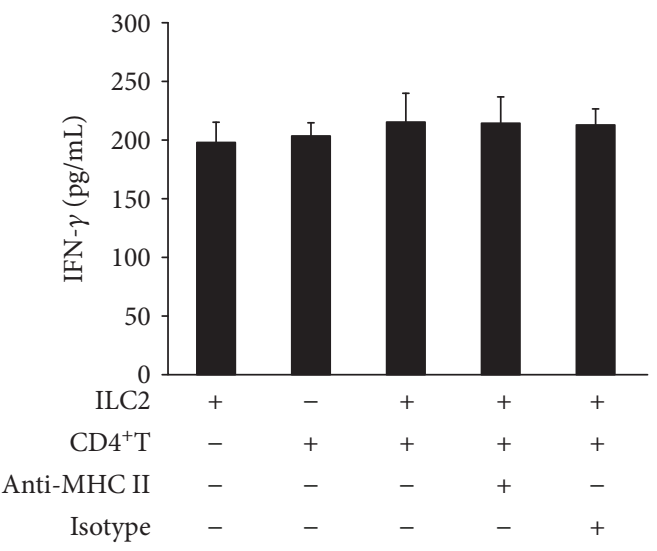

(d)

Figure 5: Cytokines in the supernatant of $\mathrm{CD}^{+} \mathrm{T}$ cell coculture with ILC2. (a) IL-4, (b) IL-5, (c) IL-13, and (d) IFN- $\gamma$ in the coculture supernatant were tested by ELISA. Data were shown as mean \pm SD. Compared with the ILC2 group, ${ }^{*} P<0.05$; compared with the CD $4{ }^{+}$ T group, ${ }^{\#} P<0.01$; compared with the ILC2: $\mathrm{CD} 4{ }^{+} \mathrm{T}$ cell coculture group, ${ }^{\triangle} P<0.05$.

induce the differentiation of $\mathrm{CD} 4^{+} \mathrm{T}$ cells into Th2 by high expression of MHC II and promote the high expression of Th2-type cytokines, but its effect on Th1 cells was not significant. Therefore, MHC II ${ }^{+}$ILC2 could promote the shift of Th2/Th1 balance to Th2 direction in AECOPD.

\section{Discussion}

The main pathological features of COPD are chronic inflammation of the airway mucosa [27]. Moreover, the T cellmediated adaptive immune response is one of the important factors leading to the persistence and amplification of chronic inflammation of the lungs [28]. Study has demonstrated that the high inflammatory response of the COPD airway was mainly caused by the imbalance of Th cells [29]. According to the different cytokines, Th cells can be mainly divided into Th1 and Th 2 cells. IFN- $\gamma$ and IL- 4 are the characteristic cytokines of Th1 and Th2 cells, respectively [30]. Normally, Th1/Th2 cells are in a relatively balanced state under normal conditions. However, studies have shown that there are imbalances of Th1/Th2 in different periods of COPD $[10,31]$. In this study, we found that Th1 cells gradually increased in stable phase of COPD and AECOPD, and the expression of IFN- $\gamma$ also showed the same trend. In con- trast, the number of Th2 cells increased significantly, along with the serum IL-4 level. Meanwhile, the Th2/Th1 ratio was decreased in patients with stable COPD whereas it increased in patients with AECOPD, indicating that the Th2/Th1 balance is shifted to Th1 response in stable COPD while it shifted to Th2 response in AECOPD.

Studies [32-34] have shown that ILC2 is involved in the pathogenesis of COPD. We found that the levels of ILC2associated transcription factors of ROR $\alpha$ mRNA, GATA3 mRNA, and CRTH2 mRNA were significantly increased in patients with stable COPD and were even higher in AECOPD patients. At the same time, flow cytometry also showed that ILC2s in the peripheral blood of the COPD group and the AECOPD group increased significantly, suggesting that ILC2s play a certain biological role in the process of COPD.

Many studies have shown the important role of ILC2s in Th2-type responses $[18,19]$. Earlier, ILC2s were named as NHCs (natural helper cells) [35], nuocytes [13], or Ih2 [36]. This cell group differs from lymphoid progenitor or lymphoid tissue-inducing cells and does not express Lineage (Lin) marker. However, it expresses c-Kit, Sca-1, IL-7R, and IL-33R (T1/ST2) [37]. Like Th2 cells, ILC2s secrete IL-5 and IL-13 and participate in processes such as antihelminth 
infection [38], tissue repair after influenza virus infection [39], and allergic asthma [40]. Similar to Th2 cells, ILC2s are widely found in the intestine, mesenteric lymph nodes, lungs, lung draining lymph nodes, trachea, spleen, liver, Peyer's knot, skin, animal fat, and blood [41]. A large number of studies $[42,43]$ have shown that ILC2s can rapidly secrete Th2-type cytokines and are the main source of Th2-type cytokines. Moreover, studies have suggested an increased infiltration of ILC2s in tissues from patients with chronic type 2 inflammation, such as those with atopic dermatitis and nasal polyps $[44,45]$. ILC2s might also play a previously unanticipated role in the initiation of Th2-type immunity.

Von Burg et al. found that ILC2s not only played an important role in early innate immunity but could also regulate adaptive cellular immunity by changing the direction of $\mathrm{CD}^{+}{ }^{\mathrm{T}}$ cell differentiation [20]. Cytokines are one of the factors for the regulation of Th2 differentiation, and IL- 2 is critical for the proliferation of Th2 cells in the presence of ILC2s. IL-2 is expressed by T cells following CD28 ligation [46, 47] and plays an important role in Th2 differentiation via STAT5a signaling [48]. Notably, we found that the CD28 ligand CD80 was highly expressed on ILC2 of AECOPD patients, suggesting that ILC2s have the capacity to interact with $\mathrm{T}$ cells and contribute to their type 2 polarization.

Studies have shown that MHC class II molecules on APC are also involved in the regulation of the differentiation process of Th2 cells $[49,50]$. Moreover, studies [18, 51] have found that ILC2s also express MHC class II molecules and are involved in the regulation of Th2 cell differentiation. Here, we found that ILC2 in patients with stable COPD expressed low levels of MHC II. However, the level of MHC II on the surface of ILC2s was significantly elevated in AECOPD patients, and its expression level was positively correlated with the number of Th2 cells. Therefore, we believe that in AECOPD, ILC2s with high expression of MHC II are likely to play a similar APC function and interact with $\mathrm{T}$ cell receptor through $\mathrm{MHC}$ class II molecules to promote the differentiation of Th2 cells, eventually leading to AECOPD Th1/Th2 balance shift to Th2 responses. The results of in vitro coculture of ILC2 and $\mathrm{CD}^{+}{ }^{+} \mathrm{T}$ cells further showed that high expression of MHC II in AECOPD ILC2s promoted the differentiation of Th2 cells and the expression of Th2 cytokines. Moreover, this effect was inhibited after blocking with anti-MHC II antibodies. At the same time, in this study, we did not observe the differentiation of $\mathrm{CD}^{+}$cells into Th1 cells by $\mathrm{MHC}$ class II molecules. Thus, ILC2s can interact with $\mathrm{CD} 4^{+} \mathrm{T}$ cells, providing new insights into the underlying mechanisms of Th2-type immune-mediated diseases.

\section{Conclusions}

In summary, by highly expressing MHC II, ILC2 may function as APC, promoting Th2/Th1 balance to Th2 shift in AECOPD patients. Therefore, $\mathrm{MHC} \mathrm{II}^{+} \mathrm{ILC} 2$ may be a new target for clinical immunoassay and treatment of AECOPD. However, the underlying mechanism of ILC2 in COPD inflammatory response and pathological processes remains unclear and needs to be further studied.

\section{Data Availability}

The data used to support the findings of this study are available from the corresponding authors upon request.

\section{Conflicts of Interest}

The authors declare that there is no conflict of interest regarding the publication of this paper.

\section{Acknowledgments}

This work was supported by National Natural Science Foundation Regional Fund Project (No. 81760793) and funds for the Xinjiang Key Construction Project of the 13th Five-Year Plan (basic medicine).

\section{References}

[1] H. K. Yoon, Y. B. Park, C. K. Rhee, J. H. Lee, Y. M. Oh, and Committee of the Korean COPD Guideline 2014, "Summary of the chronic obstructive pulmonary disease clinical practice guideline revised in 2014 by the Korean Academy of Tuberculosis and Respiratory Disease," Tuberculosis and Respiratory Diseases, vol. 80, no. 3, pp. 230-240, 2017.

[2] M. I. Restrepo, O. Sibila, and A. Anzueto, "Pneumonia in patients with chronic obstructive pulmonary disease," Tuberculosis and Respiratory Diseases, vol. 81, no. 3, pp. 187-197, 2018.

[3] B. Wei and C. Sheng Li, "Changes in Th1/Th2-producing cytokines during acute exacerbation chronic obstructive pulmonary disease," Journal of International Medical Research, vol. 46, no. 9, pp. 3890-3902, 2018.

[4] H. Chen, Y. Wang, C. Bai, and X. Wang, "Alterations of plasma inflammatory biomarkers in the healthy and chronic obstructive pulmonary disease patients with or without acute exacerbation," Journal of Proteomics, vol. 75, no. 10, pp. 2835-2843, 2012.

[5] J. Vestbo, S. S. Hurd, and R. Rodriguez-Roisin, "The 2011 revision of the global strategy for the diagnosis, management and prevention of COPD (GOLD) - why and what?," The Clinical Respiratory Journal, vol. 6, no. 4, pp. 208-214, 2012.

[6] Y. Q. Cao, L. X. Dong, and J. Cao, "Pulmonary embolism in patients with acute exacerbation of chronic obstructive pulmonary disease," Chinese Medical Journal, vol. 131, no. 14, pp. 1732-1737, 2018.

[7] B. B. Chen, Z. H. Li, and S. Gao, "Circulating miR-146a/b correlates with inflammatory cytokines in COPD and could predict the risk of acute exacerbation COPD," Medicine, vol. 97, no. 7, p. e9820, 2018.

[8] G. Turato, R. Zuin, and M. Saetta, "Pathogenesis and pathology of COPD," Respiration, vol. 68, no. 2, pp. 117-128, 2001.

[9] M. G. Cosio, J. Majo, and M. G. Cosio, "Inflammation of the airways and lung parenchyma in COPD: Role of T Cells," Chest, vol. 121, no. 5, Supplement, pp. 160s-165s, 2002.

[10] J. Sun, T. Liu, Y. Yan et al., "The role of Th1/Th2 cytokines played in regulation of specific $\mathrm{CD} 4{ }^{+}$Th1 cell conversion and activation during inflammatory reaction of chronic obstructive pulmonary disease," Scandinavian Journal of Immunology, vol. 88, no. 1, article e12674, 2018. 
[11] M. Tsoumakidou, N. Tzanakis, G. Chrysofakis, D. Kyriakou, and N. M. Siafakas, "Changes in sputum T-lymphocyte subpopulations at the onset of severe exacerbations of chronic obstructive pulmonary disease," Respiratory Medicine, vol. 99, no. 5, pp. 572-579, 2005.

[12] M. R. Karta, D. H. Broide, and T. A. Doherty, "Insights into group 2 innate lymphoid cells in human airway disease," Current Allergy and Asthma Reports, vol. 16, no. 1, p. 8, 2016.

[13] D. R. Neill, S. H. Wong, A. Bellosi et al., "Nuocytes represent a new innate effector leukocyte that mediates type-2 immunity," Nature, vol. 464, no. 7293, pp. 1367-1370, 2010.

[14] J. von Moltke, M. Ji, H.-E. Liang, and R. M. Locksley, “Tuftcell-derived IL-25 regulates an intestinal ILC2-epithelial response circuit," Nature, vol. 529, no. 7585, pp. 221-225, 2016.

[15] J. B. Lee, C. Y. Chen, B. Liu et al., "IL-25 and CD4 ${ }^{+} \mathrm{T}_{\mathrm{H}} 2$ cells enhance type 2 innate lymphoid cell-derived IL-13 production, which promotes IgE-mediated experimental food allergy," Journal of Allergy and Clinical Immunology, vol. 137, no. 4, pp. 1216-1225.e5, 2016.

[16] H. Hammad, M. Plantinga, K. Deswarte et al., "Inflammatory dendritic cells-not basophils-are necessary and sufficient for induction of Th2 immunity to inhaled house dust mite allergen," The Journal of Experimental Medicine, vol. 207, no. 10, pp. 2097-2111, 2010.

[17] C. Ohnmacht, C. Schwartz, M. Panzer, I. Schiedewitz, R. Naumann, and D. Voehringer, "Basophils orchestrate chronic allergic dermatitis and protective immunity against helminths," Immunity, vol. 33, no. 3, pp. 364-374, 2010.

[18] C. J. Oliphant, Y. Y. Hwang, J. A. Walker et al., "MHCIImediated dialog between group 2 innate lymphoid cells and $\mathrm{CD}^{+} \mathrm{T}$ cells potentiates type 2 immunity and promotes parasitic helminth expulsion," Immunity, vol. 41, no. 2, pp. 283-295, 2014.

[19] T. Y. F. Halim, C. A. Steer, L. Mathä et al., "Group 2 innate lymphoid cells are critical for the initiation of adaptive $\mathrm{T}$ helper 2 cell-mediated allergic lung inflammation," Immunity, vol. 40, no. 3, pp. 425-435, 2014.

[20] N. von Burg, G. Turchinovich, and D. Finke, "Maintenance of immune homeostasis through ILC/T cell interactions," Frontiers in Immunology, vol. 6, p. 416, 2015.

[21] C. Donovan, M. R. Starkey, R. Y. Kim et al., "Roles for T/B lymphocytes and ILC2s in experimental chronic obstructive pulmonary disease," Journal of Leukocyte Biology, vol. 105, no. 1, pp. 143-150, 2019.

[22] N. A. Hanania and D. D. Marciniuk, "A unified front against COPD: clinical practice guidelines from the American College of Physicians, the American College of Chest Physicians, the American Thoracic Society, and the European Respiratory Society," Chest, vol. 140, no. 3, pp. 565-566, 2011.

[23] J. Mjösberg, J. Bernink, K. Golebski et al., "The transcription factor GATA3 is essential for the function of human type 2 innate lymphoid cells," Immunity, vol. 37, no. 4, pp. 649659, 2012.

[24] T. Hoyler, C. S. N. Klose, A. Souabni et al., "The transcription factor GATA-3 controls cell fate and maintenance of type 2 innate lymphoid cells," Immunity, vol. 37, no. 4, pp. 634648, 2012.

[25] A. Mortha and K. Burrows, "Cytokine networks between innate lymphoid cells and myeloid cells," Frontiers in Immunology, vol. 9, p. 191, 2018.
[26] J. M. Mjösberg, S. Trifari, N. K. Crellin et al., "Human IL-25and IL-33-responsive type 2 innate lymphoid cells are defined by expression of CRTH2 and CD161," Nature Immunology, vol. 12, no. 11, pp. 1055-1062, 2011.

[27] R. Watanabe and D. Inoue, Clinical Calcium, vol. 28, no. 12, pp. 1647-1652, 2018, Secondary osteoporosis. Chronic obstructive pulmonary disease:COPD.

[28] S. G. Kalathil, A. A. Lugade, V. Pradhan et al., "T-regulatory cells and programmed death $1^{+} \mathrm{T}$ cells contribute to effector T-cell dysfunction in patients with chronic obstructive pulmonary disease," American Journal of Respiratory and Critical Care Medicine, vol. 190, no. 1, pp. 40-50, 2014.

[29] B. Lee, E. Ko, J. Lee et al., "Soluble common gamma chain exacerbates COPD progress through the regulation of inflammatory $\mathrm{T}$ cell response in mice," International Journal of Chronic Obstructive Pulmonary Disease, vol. 12, pp. 817-827, 2017.

[30] I. Raphael, S. Nalawade, T. N. Eagar, and T. G. Forsthuber, "T cell subsets and their signature cytokines in autoimmune and inflammatory diseases," Cytokine, vol. 74, no. 1, pp. 5-17, 2015.

[31] K. F. Chung, "Cytokines as targets in chronic obstructive pulmonary disease," Current Drug Targets, vol. 7, no. 6, pp. 675681, 2006.

[32] K. C. De Grove, S. Provoost, F. M. Verhamme et al., "Characterization and quantification of innate lymphoid cell subsets in human lung," Plos One, vol. 11, no. 1, article e0145961, 2016.

[33] J. S. Silver, J. Kearley, A. M. Copenhaver et al., "Inflammatory triggers associated with exacerbations of COPD orchestrate plasticity of group 2 innate lymphoid cells in the lungs," Nature Immunology, vol. 17, no. 6, pp. 626-635, 2016.

[34] G. P. Anderson, "Advances in understanding COPD," F1000Research, vol. 5, article 2392, 2016.

[35] K. Moro, T. Yamada, M. Tanabe et al., "Innate production of $\mathrm{T}_{\mathrm{H}} 2$ cytokines by adipose tissue-associated c-Kit ${ }^{+} \mathrm{Sca}-1^{+}$lymphoid cells," Nature, vol. 463, no. 7280, pp. 540-544, 2010.

[36] A. E. Price, H. E. Liang, B. M. Sullivan et al., "Systemically dispersed innate IL-13-expressing cells in type 2 immunity," Proceedings of the National Academy of Sciences of the United States of America, vol. 107, no. 25, pp. 11489-11494, 2010.

[37] A. Diefenbach, M. Colonna, and S. Koyasu, "Development, differentiation, and diversity of innate lymphoid cells," Immunity, vol. 41, no. 3, pp. 354-365, 2014.

[38] C. C. Motran, L. Silvane, L. S. Chiapello et al., "Helminth infections: recognition and modulation of the immune response by innate immune cells," Frontiers in Immunology, vol. 9, p. 664, 2018.

[39] B. C. Mindt, J. H. Fritz, and C. U. Duerr, "Group 2 innate lymphoid cells in pulmonary immunity and tissue homeostasis," Frontiers in Immunology, vol. 9, p. 840, 2018.

[40] Y. Zhou, W. Wang, C. Zhao et al., "Prostaglandin $\mathrm{E}_{2}$ inhibits group 2 innate lymphoid cell activation and allergic airway inflammation through E-prostanoid 4-cyclic adenosine monophosphate signaling," Frontiers in Immunology, vol. 9, p. 501, 2018.

[41] M. R. Karta, P. S. Rosenthal, A. Beppu et al., “ $\beta_{2}$ integrins rather than $\beta_{1}$ integrins mediate Alternaria-induced group 2 innate lymphoid cell trafficking to the lung," Journal of Allergy and Clinical Immunology, vol. 141, no. 1, pp. 329-338.e12, 2018. 
[42] C. S. Hardman, Y. L. Chen, M. Salimi et al., "CD1a presentation of endogenous antigens by group 2 innate lymphoid cells," Science Immunology, vol. 2, no. 18, p. eaan5918, 2017.

[43] J. Xu, J. Guardado, R. Hoffman et al., "IL33-mediated ILC2 activation and neutrophil IL5 production in the lung response after severe trauma: a reverse translation study from a human cohort to a mouse trauma model," PLOS Medicine, vol. 14, no. 7, article e1002365, 2017.

[44] L. Y. Drake, K. Iijima, and H. Kita, "Group 2 innate lymphoid cells and CD4+ T cells cooperate to mediate type 2 immune response in mice," Allergy, vol. 69, no. 10, pp. 1300-1307, 2014.

[45] B. S. Kim, M. C. Siracusa, S. A. Saenz et al., "TSLP elicits IL-33independent innate lymphoid cell responses to promote skin inflammation," Science Translational Medicine, vol. 5, no. 170, article 170ra16, 2013.

[46] R. A. Seder, R. N. Germain, P. S. Linsley, and W. E. Paul, "CD28-mediated costimulation of interleukin 2 (IL-2) production plays a critical role in T cell priming for IL-4 and interferon gamma production," Journal of Experimental Medicine, vol. 179, no. 1, pp. 299-304, 1994.

[47] H. Yamane, J. Zhu, and W. E. Paul, "Independent roles for IL-2 and GATA-3 in stimulating naive $\mathrm{CD}^{+} \mathrm{T}$ cells to generate a Th2-inducing cytokine environment," Journal of Experimental Medicine, vol. 202, no. 6, pp. 793-804, 2005.

[48] J. Cote-Sierra, G. Foucras, L. Guo et al., "Interleukin 2 plays a central role in Th2 differentiation," Proceedings of the National Academy of Sciences of the United States of America, vol. 101, no. 11, pp. 3880-3885, 2004.

[49] S. J. Jenkins, G. Perona-Wright, and A. S. MacDonald, "Full development of Th2 immunity requires both innate and adaptive sources of CD154," The Journal of Immunology, vol. 180, no. 12, pp. 8083-8092, 2008.

[50] A. T. Phythian-Adams, P. C. Cook, R. J. Lundie et al., "CD11c depletion severely disrupts Th2 induction and development in vivo," The Journal of Experimental Medicine, vol. 207, no. 10, pp. 2089-2096, 2010.

[51] A. S. Mirchandani, A. G. Besnard, E. Yip et al., "Type 2 innate lymphoid cells drive $\mathrm{CD} 4{ }^{+}$Th2 cell responses," The Journal of Immunology, vol. 192, no. 5, pp. 2442-2448, 2014. 


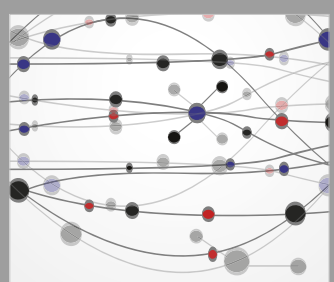

The Scientific World Journal
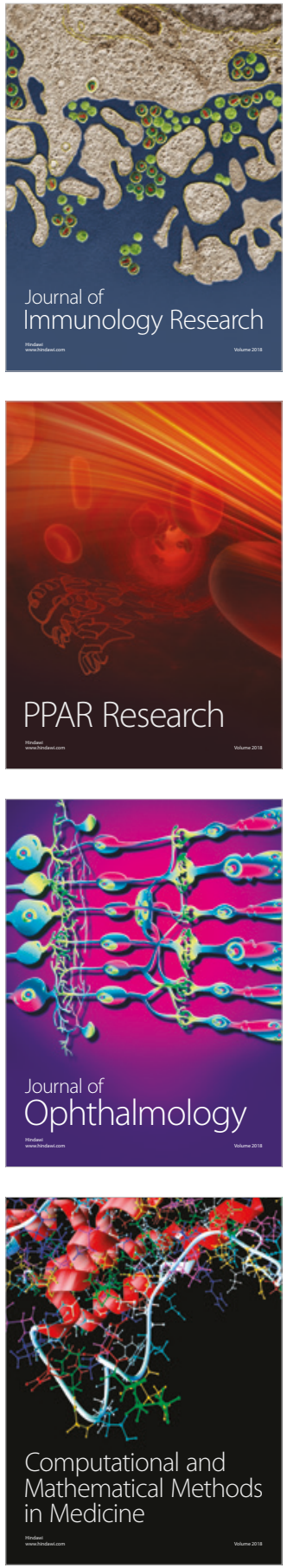

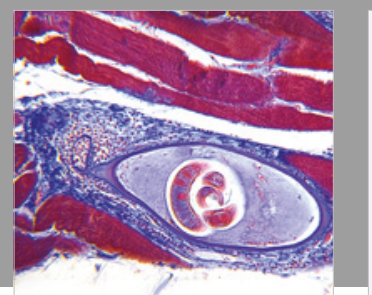

Gastroenterology Research and Practice

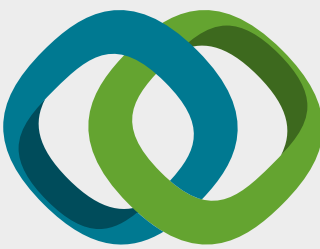

\section{Hindawi}

Submit your manuscripts at

www.hindawi.com
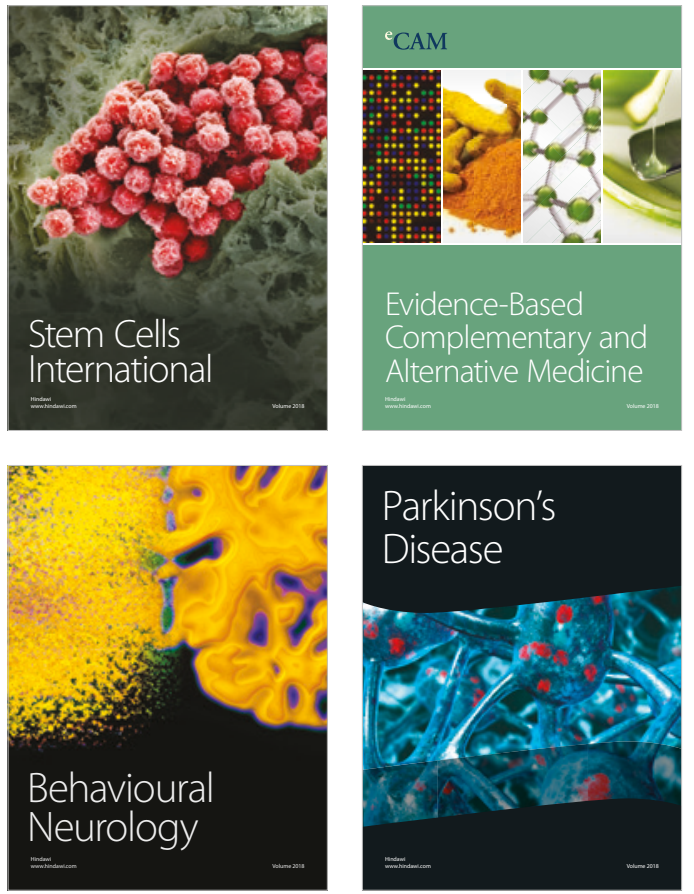

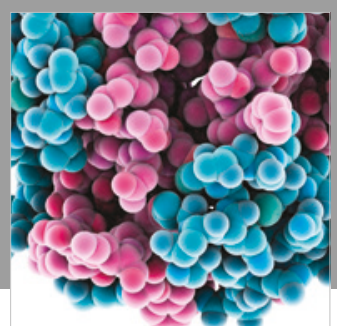

ournal of

Diabetes Research

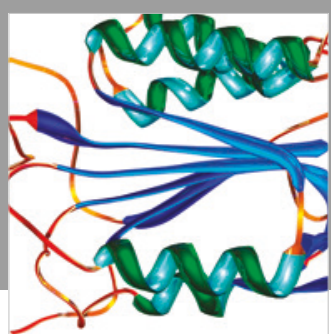

Disease Markers
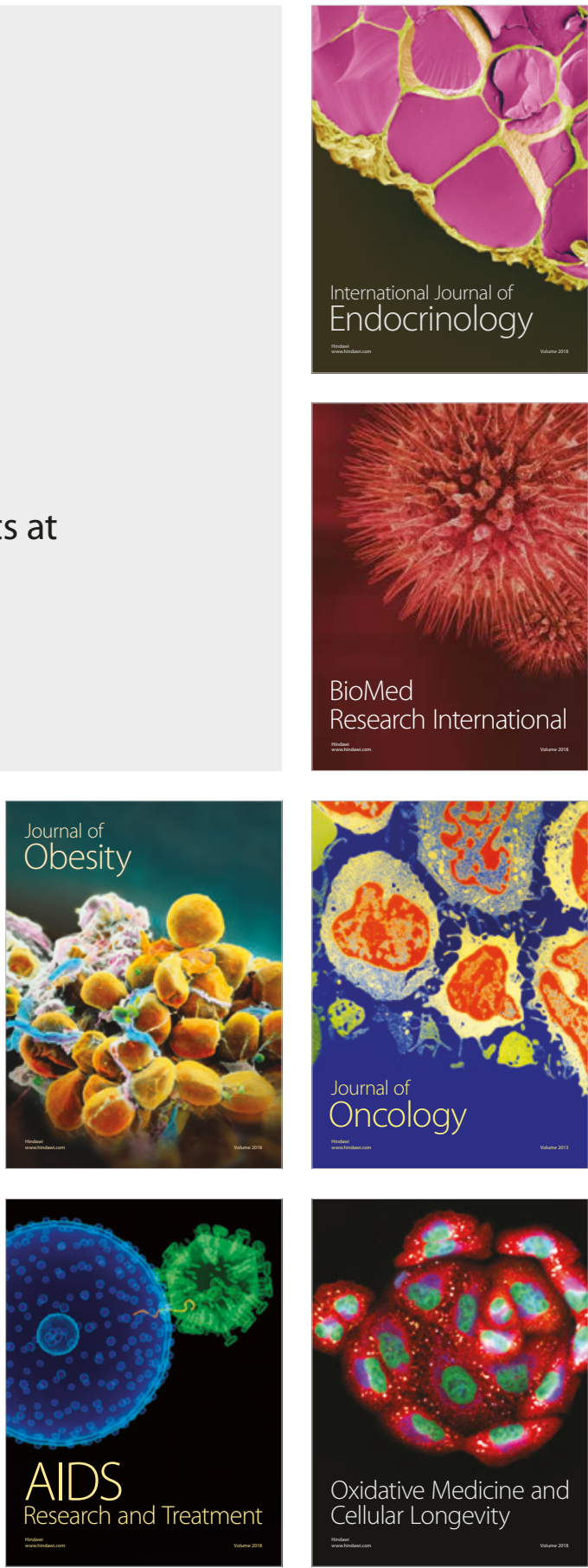